Weber-Wellstein, Encyklopädie der Elementarmathematik. Erster Band: Arithmetik, Algebra und Analysis. By Heinrich Weber. Vierte Auflage neubearbeitet von Paul Epstein. Leipzig und Berlin, B. G. Teubner, 1922. xvi $+568 \mathrm{pp}$.

The first edition of this standard and valuable work was reviewed in this Bulletis (vol. 10, p. 200) by David Eugene Smith. A brief notice of the third edition was published by F. W. Owens (Bullemers, vol. 17, p. 546). Since the publication of the latter, both the original authors have died. The new (fourth) edition of the first volume appears under the editorship of Paul Epstein. A critical estimate of such a standard work is unnecessary, especially so since no radical changes appear to have taken place. The most noteworthy is the omission of the short chapter on differentiation, which was introduced first in the second edition, and which is now again abandoned partly to save space for material that appears to the present editor more important and partly because a mere brief introduction is not in keeping with plan of the work. An extended treatment was in any case out of the question. Opinions will probably differ as to the validity of the reasons assigned for this omission; but to the present reviewer they appear altogether reasonable. The question as to the meaning to be attached to the term "elementary mathematics" is in any case a difficult one. The meaning accepted by the present author seems to be at least as reasonable as any other. The present edition is in spite of the omission noted somewhat larger than the previous one, owing to the inclusion of some new material and the elaboration of some of the older material. The preface to the present edition indicates these additions, so that they need not be listed here. The historical and bibliographical notes seem to have been distinctly improved. There can be no doubt that the new edition will adequately fill the place in our standard reference literature which the earlier editions filled with such marked success.

\title{
J. W. Young
}

Über die Hypothesen welche der Geometrie zu Grunde liegen. By B. Riemann.

Neu herausgegeben und erläutert von $\mathrm{H}$. Weyl. Second edition. Berlin, Julius Springer, 1921. vi $+47 \mathrm{pp}$.

This reprint of Riemann's famous Habilitationsschrift will be welcomed by many. It is one of those few papers which are of permanent and fundamental interest to all who are concerned with the consideration of the general foundation and formulation of fundamental concepts. It is of special value at the present time when the theory of relativity is demanding so much attention. In the last section of his paper Riemann exhibits an almost uncanny insight which Einstein's results finally corroborate. Weyl's notes are very helpful, not only in carrying out in some detail a number of the analytic computations which in Riemann's text are only indicated, but also in giving significant references to later related literature. These notes occupy twenty-four of the forty-seven pages of the pamphlet.

J. W. YounG 